\title{
Salim Bachi, Le Silence de Mahomet
}

\section{Ilaria Vitali}

\section{(2) OpenEdition}

\section{Journals}

\section{Edizione digitale}

URL: http://journals.openedition.org/studifrancesi/8404

DOI: 10.4000/studifrancesi.8404

ISSN: 2427-5856

\section{Editore}

Rosenberg \& Sellier

\section{Edizione cartacea}

Data di pubblicazione: 1 mai 2009

Paginazione: 219

ISSN: 0039-2944

\section{Notizia bibliografica digitale}

Ilaria Vitali, «Salim Bachi, Le Silence de Mahomet», Studi Francesi [Online], 157 (LIII | I) | 2009, online dal 30 novembre 2015, consultato il 07 janvier 2021. URL: http://journals.openedition.org/studifrancesi/ 8404 ; DOI: https://doi.org/10.4000/studifrancesi.8404

\section{Questo documento è stato generato automaticamente il 7 janvier 2021}

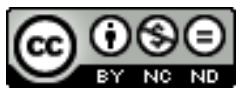

Studi Francesi è distribuita con Licenza Creative Commons Attribuzione - Non commerciale - Non opere derivate 4.0 Internazionale. 


\title{
Salim Bachi, Le Silence de Mahomet
}

\author{
Ilaria Vitali
}

\section{NOTIZIA}

SALIM BACHI, Le Silence de Mahomet, Paris, Gallimard, 2008, pp. 350.

1 Non è una biografia di Maometto l'ultima prova letteraria dell'autore algerino Salim Bachi, ma un vero e proprio romanzo in cui quattro voci si alternano per tracciare un ritratto del Profeta. L'opera, ambientata intorno al 600 d.C. tra la Mecca e Medina, le sabbie del deserto e la città di Gerusalemme, delinea il volto di un uomo singolare, orfano arricchitosi con il primo matrimonio, poi facoltoso mercante e carovaniere, prima di essere toccato dalla parola divina. A tracciare il primo profilo della figura di questo homme passionné che diventerà prophète de l'Islam, è la sua prima moglie, Khadija. Attraverso la sua voce, Maometto appare come un giovane per certi versi ancora inesperto rispetto a lei, più anziana, che lo sposò in seconde nozze. In questa sezione del romanzo, Maometto è presentato prima di tutto come un uomo, un «marito» - è descritta anche la vita amorosa dei due coniugi - in cui Khadija scorge però già il destino di un profeta al punto da divenire la prima convertita all'Islam. La seconda voce ad intessere il racconto della vita di Maometto è quella del suo migliore amico, il califfo Abou Bakr, padre di colei che diventerà la sua sposa prediletta, Aïcha. Pagina dopo pagina, si delinea in modo sempre più netto il ritratto di un uomo che ha vissuto profondamente il suo tempo, pur superandone i confini. Il terzo a raccogliere il testimone della narrazione è il generale Khalid Ibn Al-Walid, che guidò l'Irak nel corso di epiche battaglie e fu avversario di Maometto prima di convertirsi anch'egli all'Islam. In questa sezione sono messe in luce le qualità di condottiero e uomo di stato del Profeta, «conquérant impitoyable». A chiudere la complessa tessitura narrativa è la giovane e celebre Aïcha, la moglie prediletta, divenuta sposa di Maometto all'età di soli nove anni. Figura tra le più interessanti dell'Islam, Aïcha manterrà fino alla morte un rapporto privilegiato con il Profeta, senza risparmiargli tuttavia alcune critiche sulle restrizioni imposte alle donne dalla «nuova» religione. È sulle sue ginocchia che Maometto muore, dopo averle rivelato un'ultima, temibile profezia: «Un jour, l'Islam 
sera l'étranger qu'il a commencé par être. [...] Alors tout sera licite pour ces hommes. Ils prétendront des choses fausses sur ma vie. Ils dresseront le portrait d'un autre homme qu'ils nommeront Mohammad et qu'ils agiteront selon les circonstances. Ils justifieront ainsi leurs turpitudes et dissimuleront leurs faiblesses. Ils seront hors de la sphère de Dieu» (p. 350).

2 Con questo romanzo, Bachi continua il suo ciclo letterario «religioso», - sviluppato accanto al cosiddetto «ciclo di Cyrtha» che comprende i suoi primi romanzi ambientati nell'omonima città immaginaria - cominciato nel 2003 con Tuez-les tous, che raccontava l'11 settembre vissuto nei panni di uno dei terroristi islamici responsabili dell'attacco al World Trade Center. Come in quel testo, anche in questo appaiono numerosi versetti coranici - qui nella traduzione di Denise Masson edita nella collana della «Pléiade»intessuti nel racconto che richiama, con la sua prosa a tratti rimata, l'incedere del testo sacro dell'Islam. Molto interessanti le differenze stilistiche che sottolineano il cambio di voci da un narratore all'altro percepibile in modo netto, così come il lavoro certosino sulla lingua, alla ricerca di termini mutuati dall'arabo, come «alcôve», che, uniti al ritmo cadenzato tipico della recitazione coranica, danno un aspetto «orientale» alla narrazione. Numerosi gli spunti di dibattito offerti dal romanzo, a partire dall'analfabetismo ancora discusso di Maometto (che si basa sull'ambivalenza del termine ummî, «analfabeta», ma anche "uomo rimasto allo stato di natura»), qui descritto invece come un «divoratore di libri», fino all'obbligo per le donne islamiche di portare il velo, imposizione in parte criticata da Aïcha.

3 Un'opera avvincente, concepita dall'autore prima di tutto come un «romanzo d'avventura» che mostri al lettore un ritratto inedito di una figura storica cruciale, ancora largamente sconosciuta. 